\title{
GESTIÓN DEL PATRIMONIO AGRÍCOLA ECLESIÁSTICO A TRAVÉS DE LOS ARRENDAMIENTOS EN LA SEVILLA DE LOS SIGLOS XVI Y XVII (1570-1620). EL CONVENTO DE SANTA CLARA DE CARMONA
}

\author{
POR \\ JUAN CARPIO ELÍAS ${ }^{1}$ \\ Universidad de Sevilla
}

\section{RESUMEN}

Este trabajo pretende abordar la gestión de los abundantes bienes rústicos del clero. Partimos de la base de que se sigue una línea de actuación que proporciona rentabilidad y seguridad. La investigación emplea documentación notarial y específicamente eclesiástica de Sevilla y Carmona en los siglos XVI y XVII. Dentro de la heterogeneidad del clero, analizamos un caso, el del convento de Santa Clara de Carmona. El estudio confirma la eficiencia del clero sevillano en la administración de sus patrimonios rústicos siguiendo el sistema de explotación predominante en la época: los arrendamientos.

PALABRAS CLAVE: clero; bienes rústicos; arrendamientos; rentabilidad; convento.

\section{MANAGEMENT OF THE ECCLESIASTICAL AGRICULTURAL HERITAGE THROUGH LEASES IN SEVILLE OF THE $16^{\text {TH }}$ AND $17^{\text {TH }}$ CENTURIES (1570-1620). THE CONVENT OF SANTA CLARA DE CARMONA}

\begin{abstract}
His paper aims to address the management of the abundant rustic goods of the clergy. We start from the base that follows a line of action that provides profitability and security. The investigation employs notarial and specifically ecclesiastical documentation of Seville and Carmona in the sixteenth and seventeenth centuries. Within the heterogeneity of the clergy, we analyze a case, that of the convent of Santa Clara de Carmona. The study confirms the efficiency of the Sevillian clergy in the administration of their rustic heritage following the prevailing system of exploitation at the time: the leases.
\end{abstract}

KEY WORDS: clergy; rustic goods; leases; profitability; convent.

Cómo CITAR ESTE ARTículo / CitATION: Carpio Elías, Juan. 2019. «Gestión del patrimonio agrícola eclesiástico a través de los arrendamientos en la Sevilla de los siglos XVI y XVII (1570-1620). El convento de Santa Clara de Carmona». Hispania Sacra 71, 144: 493-502. https://doi.org/10.3989/hs.2019.035

\author{
Recibido/Received 13-04-2018 \\ Aceptado/Accepted $\quad$ 05-10-2018
}

\section{INTRODUCCIÓN}

Ha pasado ya mucho tiempo desde que se puso de manifiesto la importancia de los contratos de arrendamiento de propiedades rústicas para el conocimiento de las sociedades rurales durante el Antiguo Régimen. ${ }^{2}$ Sin embargo, pensamos

\footnotetext{
1 jcarpio4@us.es /

ORCID iD: https://orcid.org/0000-0001-9214-5220

2 Podemos citar como ejemplo las Actas del Congreso de Historia Rural celebrado en octubre de 1981. En ellas figuraban trabajos de gran
}

que no se ha avanzado lo suficiente, especialmente, en lo concerniente a los siglos XVI y XVII, sobre todo, cuando atravesamos una ya larga etapa en la que la historiografía rural languidece en medio de una atonía y desinterés por las cuestiones agrarias. A pesar de la débil producción de estudios no se ha cuestionado el papel dominante de los arrendamientos en el ámbito de la economía agraria. Esta afirmación la

interés sobre esta temática como el de Álvarez Vázquez 1984: 613-623, o el de Chacón Jiménez 1984: 625-644. 
consideramos igualmente válida a la hora de estudiar las propiedades rústicas del clero en el reino de Sevilla.

El mundo eclesiástico ha venido atrayendo la atención historiográfica, pero desde otras vertientes que ayudan a entender un estamento tan heterogéneo. Esta característica, consustancial de este grupo social aporta una enorme complejidad que, casi determina un tratamiento excesivamente parcelado y fragmentado, que afecta, incluso, a los estudios de síntesis. ${ }^{3}$ No obstante, seguimos necesitados de profundizar en sus bases económicas, más concretamente, en sus bienes rústicos y, sobre todo, más que en la propiedad, en su explotación y gestión. A esa finalidad pretende contribuir este trabajo.

Las fuentes documentales que hemos utilizado proceden de 4 vertientes:

- Archivo de Protocolos Notariales de Sevilla, en especial para el período de 1570-1620. En este caso, la documentación forma parte de una investigación mayor que afecta al conjunto de la sociedad. ${ }^{4} \mathrm{El}$ número de contratos empleados en este trabajo, referidos al clero ha sido de 227.

- Archivo del Cabildo de la Catedral de Sevilla. Dentro de su heterogeneidad, buscando los puntos de contacto con los contratos de arrendamiento, al mismo tiempo que sirviera de complemento, hemos centrado nuestra atención en los Libros de Heredades ${ }^{5}$ y en los Libros de Apeamientos. ${ }^{6}$

- Otro grupo de fuentes corresponde a los Protocolos Notariales del Archivo Municipal de Carmona. El análisis se ha hecho sobre el período comprendido entre 1582 y 1620, ${ }^{7}$ con un volumen de 196 contratos agrarios firmados por Santa Clara y 57 otorgados por otros conventos de la localidad y de la ciudad de Sevilla.

- Gracias a la amabilidad de la comunidad de clarisas de Carmona hemos podido también consultar una valiosa fuente, conservada dentro de su museo, como el Libro del Protocolo Mayor de la Hacienda y Bienes del convento de Santa Clara.

El planteamiento general que se aborda en los dos primeros apartados se basa en los dos primeros grupos de fuentes. El estudio de caso se sustenta en los otros dos grupos de fuentes. Tendría coherencia en sí mismo haberse centrado solamente en el convento de Santa Clara, pero el trabajo busca un enfoque complementario entre lo general y lo particular.

Respecto al período estudiado, establecemos el marco 1570-1620, pese a que tanto la documentación del cabildo

\footnotetext{
3 Rey Castelao 2009a: 197-223.

4 Dado el enorme volumen documental y las características formales y de contenido que presentan los contratos de arrendamiento optamos en su momento por practicar un sistema de cortes o calas, recogiendo información solamente de los años acabados en 0.

5 Constituyen un conjunto de 9 libros que ininterrumpidamente abarcan desde el siglo XVI hasta el siglo XVIII, variando las fechas en que comienzan y finalizan los asientos sobre cada una de las distintas propiedades rústicas. En ellos se registran los arrendamientos que el cabildo realiza de estas fincas.

6 Se conservan solamente dos de estos libros, aunque muy completos, uno corresponde a la fecha de 1538 y el otro a la de 1630. Incorporan la descripción y límites de los elementos que configuran las propiedades.

7 La documentación presenta algunas lagunas, al faltar los legajos correspondientes a los años 1592, 1597, 1598. 1601, 1606, 1609 y 1617.
}

de la catedral como en el Libro de Bienes de Santa Clara, ofrecen algunos datos pertenecientes a fechas más avanzadas del siglo XVII. No obstante, la abrumadora mayoría de contratos comprendidos en la etapa seleccionada y la hipótesis de partida justifican la selección temporal. Aceptando todo tipo de matizaciones, seguimos considerando la validez de una Sevilla en expansión en el siglo XVI, frente a un panorama de crisis en el siglo XVII. El objetivo principal con esta periodización persigue identificar los síntomas del cambio de tendencia en una actividad económica fundamental como la explotación de la tierra.

Dentro del antiguo reino de Sevilla la procedencia de las fuentes determina que mayoritariamente el área estudiada se identifique con la ciudad de Sevilla y con las comarcas más próximas, como la Vega, la Campiña y el Aljarafe. Por su parte, la Iglesia de Sevilla cuenta con su propia organización administrativa basada en las vicarías, que a su vez comprenden un conjunto de parroquias. La vicaría puede coincidir con una única población, caso de Écija o Jerez, o contar con varios núcleos, como Carmona, que además de esta localidad incluye El Viso del Alcor, Mairena del Alcor, Fuentes y Guadajoz. $^{8}$

\section{LA ECONOMÍA AGRARIA Y EL CLERO}

La actividad agraria, pese a su potencial irregularidad, además de constituir el principal medio de subsistencia para gran parte de la población despierta interés en todos los grupos sociales. Existe la esperanza de satisfacer unos objetivos económicos muy dispares, que van desde una absoluta modestia, en la que la tierra es un pequeño complemento, al de un gran negocio del que se espera obtener pingües ganancias.

Las formas de explotación de la tierra durante la Edad Moderna presentan una gran variedad. Junto a fórmulas enfitéuticas nos encontraríamos con las medianerías y los terrazgos. Entre la primera hallamos ejemplos de la aparcería. Se trataba de un contrato de duración limitada en virtud del cual el propietario y el campesino se ponían de acuerdo para proporcionar la tierra y el trabajo respectivamente, concertando igualmente lo que cada uno debía aportar en lo referente a las semillas, los aperos y los animales a emplear. No se produce una total cesión de la tierra, por lo que puede entenderse como una fórmula intermedia entre la explotación directa y el arrendamiento. ${ }^{9}$ Por su parte, el terrazgo, bastante común en las pautas de actuación del clero regular, se aproxima más al arrendamiento. Limita su duración a un ciclo agrícola, generalmente en parcelas pequeñas y con una anticipación al riesgo y los posibles rendimientos, con lo que se suele pagar una parte proporcional de la cosecha. ${ }^{10}$ A todo ello habría que añadir la explotación directa practicada por determinadas órdenes religiosas, especialmente los jesuitas ${ }^{11}$ o los denominados contratos de esquilmo. ${ }^{12}$

8 El crecimiento de la población de la Edad Moderna encuentra reflejo en el aumento de vicarías que alcanzan el número de 41 a principios del siglo XVIII en la diócesis de Sevilla. Candau 1994: 37-50.

9 Carpio 2011: 362.

10 Borrero 2003: 58.

11 Rodríguez Molina 2004: 132.

12 El proceso no se detiene en la recolección, sino que comprende también la molienda y la obtención del aceite. El propietario cede la cosecha, una vez que es conocida su posible producción, a cambio de 
Estas formas de explotación fueron minoritarias en la sociedad andaluza y, en particular en el clero. Teniendo muy presente las diferencias regionales, incluso comarcales, el marco principal que conecta la propiedad y la explotación en torno a la tierra, estaría constituido por los arrendamientos. Esto es algo comúnmente aceptado no solo para Andalucía o el resto de la península ibérica, sino para otras latitudes europeas. ${ }^{13}$

Un grupo muy reconocible y de gran presencia en el mundo rural es el clero. Conforma un estamento demasiado complejo con una gran diversidad de situaciones sociales en su seno. Por ello, distinguimos la intervención en la vida económica de forma institucional o con carácter individual. La diferencia convencional a la hora del análisis no implica una exigencia conceptual. Usamos la participación institucional para referirnos a colectivos, fundamentalmente conventos. Se presenta como la más numerosa y probablemente la más importante desde distintos puntos de vista. Está presente en todos los cultivos, aunque porcentualmente alcanza mayor relieve en las explotaciones de olivar. Dentro de la variedad que dispone este carácter institucional destaca con personalidad propia los arrendamientos efectuados por los conventos y monasterios de las órdenes regulares. Recordemos que el momento de mayor actividad fundacional de las distintas congregaciones se enmarca entre el último tercio del siglo XVI y la primera mitad del siglo XVII. El período comprendido entre 1577 y 1624 representa el 60 $\%$ de las fundaciones de la Edad Moderna. ${ }^{14}$

En el reino de Sevilla estaban presentes todas las órdenes, algunas desde el siglo XIII, pero su situación económica era de lo más dispar. ${ }^{15}$ Casi la mitad de los contratos con esta denominada participación institucional tiene como protagonista a los conventos. Conocemos ya que lo hacen casi con carácter exclusivo desde la posición de arrendador y en su caso podemos considerarlos como propietarios. Al tratarse de comunidades, lo habitual era que figurase como otorgante una sola persona que ostentaba la representación de la institución. Podría corresponder a un prior o a un administrador profesional, como sucedía con varios conventos femeninos en los que queda constancia de cómo actúan distintos mayordomos o administradores para las diversas propiedades.

Otra institución que disponía de bienes rústicos y los explotaba mediante el arrendamiento era la fábrica de las distintas iglesias, tanto de la ciudad, como de las localidades. Existe una insuficiencia investigadora, probablemente derivada de la dificultad de las fuentes, que nos dificulta conocer en profundidad la administración de los bienes parroquiales. Su situación económica podría variar mucho en función de las áreas comarcales. ${ }^{16}$ En el Aljarafe

una renta en especie y de esa forma se desentiende de tareas complejas y laboriosas, como podía resultar la misma contratación de mano de obra para la recogida de la aceituna.

13 Marcos 2000: 216.

14 Atienza 2008: 33

15 López Martínez 1992: 45. Señala el fuerte contraste entre las propiedades de los distintos conventos y aun reconociendo que algunos de dichos conventos eran dueños de extensas fincas no puede mantenerse el carácter terrateniente para todas las órdenes religiosas.

16 Las diferencias regionales aparecen constantemente en la economía agraria de la Edad Moderna. Por ejemplo, en León los clérigos parroquiales contaban con una alta participación en la renta agraria a través de los arriendos de sus tierras. Pérez Rubio 2013: 157. las propiedades rústicas de las fábricas parroquiales son muy escasas en extensión y afectan a un corto número de parroquias. $^{17}$

Probablemente, en ese mismo subgrupo del clero secular podamos situar la mayoría de las capellanías, aunque los bienes vinculados en unas y otras serían muy diferentes en naturaleza y número de los mismos. Se habían multiplicado en las grandes ciudades. Sevilla, concretamente, pudo alcanzar las 3500 capellanías. ${ }^{18}$ Las que hemos tenido ocasión de estudiar en los contratos de arrendamiento corresponden a pequeñas propiedades, generalmente ocupadas por tierras de sembradura.

Otro grupo que podría ser un simple detentador de rentas es el de los beneficiados. La documentación analizada no permite asignar con claridad los bienes rústicos de este grupo a una institución. En el mayor número de casos lo hemos clasificado dentro de la participación individual del clero, ${ }^{19}$ salvo en los contratos en los que la propiedad territorial se arrendaba en nombre de varios beneficiados, en cuyo supuesto lo hemos incluido en el apartado de parroquias. En algunos casos, constituyen una rica institución, como la Universidad de Beneficiados de Carmona que acumuló un patrimonio rústico muy importante en el siglo XVII. ${ }^{20}$

En la Figura 1 mostramos una representación de la que hemos denominado participación institucional entre 1570 y 1620 , relativa a los contratos de arrendamiento estudiados en el reino de Sevilla.

FIGURA 1

Presencia de las distintas instituciones eclesiásticas en los arrendamientos rústicos

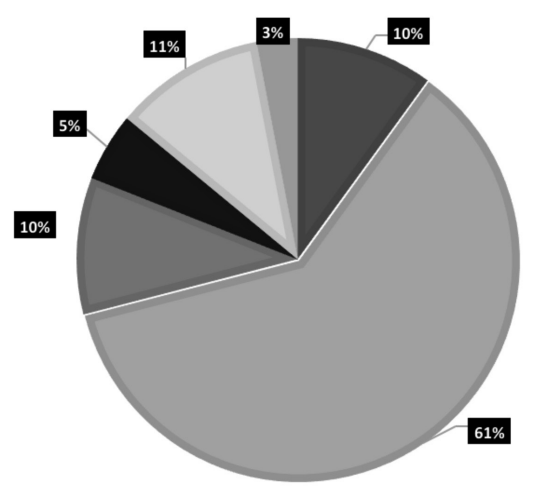

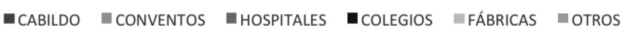

Fuente: elaboración propia. AHPS. Protocolos. 1570-1620

Cuando la actuación corresponde a lo que hemos denominado individual se reparte por mitad casi en idénticas proporciones entre arrendadores y arrendatarios, lo que constituye la gran diferencia con la participación institucional que era solamente de arrendadores. Dado el menor

17 Herrera 1980: 189.

18 Domínguez Ortiz 1973: 264.

19 A sabiendas del carácter convencional hemos adoptado el criterio de considerar participación individual y no institucional la de los beneficiados identificados con una sola persona.

20 Contaba con las rentas derivadas de 23 cortijos o hazas, más algunos olivares, 6 casas, unas casas chiquitas, unas casas tiendas, 3 tiendas, 3 tributos y un conjunto de tributos menores. Sánchez Herrero 2003: 453. 
número de casos y la variedad de situaciones ${ }^{21}$ no podemos fijar características claramente definitorias de este tipo de intervención. La hallamos relacionada con todos los cultivos. Añadir, tan solo, que otorgan los documentos con absoluta autonomía, sin valerse de la representación de otra persona, salvo en caso estrictamente necesario, como una estancia en Indias. Es probable que impere una situación perceptible en el siglo XVIII en la que una buena parte del clero rural vive en la pobreza y no dispone de bienes patrimoniales. ${ }^{22}$

\section{LA GESTIÓN DEL PATRIMONIO RÚSTICO ECLESIÁSTICO A TRAVÉS DE LOS ARRENDAMIENTOS}

Veamos respecto a Sevilla el comportamiento del clero a la hora de recurrir al sistema de arrendamientos para rentabilizar sus propiedades rústicas. Las especiales características de su organización, las funciones sociales que le estaban reservadas y la enorme cantidad de bienes rústicos que habían ido llegando a su poder, casi todos ellos con un carácter vinculado, hacían del arrendamiento uno de los sistemas más atractivos para extraer rentabilidad a estos bienes.

La mayor presencia de la propiedad eclesiástica se localiza en Sevilla y la Campiña. Una parte considerable de estas propiedades territoriales se identifica con cortijos pertenecientes a instituciones religiosas, concretamente conventos femeninos, tanto de la Campiña como de la propia ciudad. Una cuarta parte del clero sevillano que figura en la documentación consultada posee tierras en la Campiña. En esta comarca se sitúan sus ricos graneros, especialmente en el término de Carmona. Empleamos el vocablo granero a conciencia, puesto que, en todos los contratos, tanto los del siglo XVI como los del XVII, van a acordar el pago de la renta en especie, fundamentalmente pan terciado (dos partes de trigo y una de cebada), que a veces se acompaña de otros productos, como garbanzos, gallinas, paja y de un cerdo. En buena parte de la documentación se especifica que el pan terciado y los garbanzos serán encamarados dentro del monasterio en la ciudad de Sevilla. ${ }^{23}$ Este proceder confirma que el estamento eclesiástico no solamente se había convertido en un gran detentador de rentas sino en un acaparador de granos, ${ }^{24}$ lo que le posicionaba favorablemente para optimizar ganancias ante la inflación y las carestías.

Nos interesa discernir qué papel juega el clero en los contratos de arrendamiento. Los datos no dejan ningún resquicio a la duda, ya que en el $84 \%$ de los protocolos consultados procedentes del Archivo Histórico Provincial de Sevilla su actuación corresponde a la del arrendador. Es necesario ser prudente respecto a la importancia económico-social concedida al arrendador, pues en determinados casos el arrendatario puede desempeñar una actividad económica

21 Incluso en una misma comarca con localidades cercanas, predomina la heterogeneidad a la hora de establecer el nivel económico del grupo. Benítez Barea 2013: 257.

22 Candau 1994: 332.

23 Podemos suponer que estas cámaras eran de grandes dimensiones para albergar los cereales que se acumulaban por las mismas fechas, puesto que casi todos los cortijos estaban obligados a pagar la renta por Santiago (25 de julio).

24 Carpio 2017: 164. superior y sin ser propietario interviene en más o/y mayores fincas que los mismos propietarios. ${ }^{25}$ Sin embargo, en el caso del clero, como ya hemos señalado, es donde mejor encaja la supuesta identificación entre arrendador y propietario.

Las tierras que arrendaba el clero, eran explotadas mayoritariamente por labradores en el caso de la tierra calma ${ }^{26} \mathrm{y}$ hortelanos ${ }^{27}$ cuando se trataba de huertas. Tampoco resultaban ajenos a estos contratos los arrendatarios pertenecientes a las élites locales de poder, ${ }^{28}$ sobre todo, en el caso de las grandes fincas. ${ }^{29}$ Este tipo de propiedades se pregonaban y se sacaban a subasta pública, pero en la práctica los potenciales arrendatarios formaban un grupo reducido, con un perfil de labrador-ganadero muy próximo por cargos o relaciones familiares y clientelares a los círculos del poder local.

Cuando la posición que ocupa el clero en los contratos de arrendamiento es la de arrendatario su participación disminuye considerablemente, situándose en el $16 \%$ de la documentación analizada en los protocolos notariales de Sevilla. Parece difícil señalar notas cualitativas lo suficientemente nítidas de esta corta participación. La hallamos en todos los cultivos y en cualquier tipo de propiedad si atendemos a su extensión. Solía corresponder a miembros del estado eclesiástico que contraen los arrendamientos a título individual como personas independientes dotadas de su propia capacidad jurídica. Se trataba, casi siempre de clero secular, concretamente presbíteros. En general, cada uno de los casos en los que figura el clero como arrendatario nos sugiere una mentalidad capitalista o especuladora ligada al subarriendo, pues si dada sus obligaciones sociales y espirituales parece lógica la posición del clero, no queda tan evidente cuándo es la condición del arrendatario la que prevalece. Esta idea viene reforzada por el hecho de que con frecuencia no coincide la localización de los bienes objeto de arrendamiento con la residencia del clérigo o el destino donde ejerce su función eclesiástica.

En relación con los distintos cultivos conviene destacar la preponderancia de la presencia eclesiástica en los contratos de cereal, concretamente el $51,8 \%$ de todos los arrendamientos rústicos en los que interviene el clero. El principal propietario $y$, consecuentemente máximo arrendador de bienes rústicos, en general, y de la tierra calma, en particular, es el cabildo de la Santa Iglesia de Sevilla. En algunos términos como Carmona esta institución ostenta la posición de primer propietario, lo que además se ve reforzado por la naturaleza de las tierras, consideradas de primera calidad. ${ }^{30}$ En nuestro ámbito geográfico de estudio, además del cabildo de la catedral, los principales arrendadores están

\footnotetext{
25 Gamero 1998.

26 Se entiende una explotación agraria de secano, destinada fundamentalmente a cereales.

27 Estas categorías engloban realidades muy diversas. En general, un labrador sería una persona con capacidad de labrar; sin incurrir en obviedades, estaríamos aludiendo a la disposición o propiedad de unos recursos que le permitan la plena explotación de la tierra de secano. El hortelano centra su actividad, casi con exclusividad, en la explotación de la huerta.

28 Chacón 1984: 634.

29 La forma más usual y práctica de establecer los arrendamientos de estos valiosos bienes eclesiásticos era por remate, es decir, sacándolos a pública subasta.

30 Carpio 2010: 86.
} 
constituidos por el colectivo de órdenes religiosas, con una desproporción absoluta cuando de tierra calma se trata entre una mayoría de conventos femeninos y una minoría de masculinos.

En relación con el tipo de propiedad, desde el punto de vista de la extensión, no contamos con estudios definitivos sobre las posesiones de la Iglesia Existía gran variación entre los distintos cultivos y también debía influir la calidad de la tierra y su margen de productividad, ${ }^{31}$ pero este tipo de datos cualitativos no aparece en la documentación hasta el catastro de Ensenada. Aun queriendo ceñirnos a datos exclusivamente cuantitativos la falta de una unificación en las medidas que contempla diferencias, incluso, dentro de la misma comarca provoca que se convierta en una tarea casi imposible la exacta adecuación e interpretación de las medidas agrarias durante el Antiguo Régimen. ${ }^{32}$

Todo apunta a que una gran parte de estas tierras del clero estaba formando parte de las grandes propiedades..$^{33}$ De hecho, uno de los datos más significativos es que más de la mitad de estos contratos corresponden a cortijos. La documentación notarial muy rara vez aporta la superficie de que consta esta propiedad territorial. Por los cortijos que arrienda el cabildo descubrimos que no existe en absoluto una media real, con una casuística demasiado amplia, tanto en el número de hazas, como en las medidas de estas, pero superando, en cualquier supuesto, las 100 fanegas. Junto a la gran propiedad existe una importante proporción de propiedad claramente minifundista con pedazos y hazas alrededor de las 4 o 5 fanegas, incluso, con extensión inferior. Al clero lo relacionamos, pues, tanto con esta propiedad minifundista, como con un tipo de gran propiedad abocada al arrendamiento y al subarriendo, solo al alcance de poderosos labradores con una sólida capacidad inversora tanto en capital como en infraestructura agraria (aperos, animales, instalaciones, etc.). ${ }^{34}$

Si atendemos a la forma de explotación, es decir, al tiempo por el que se establece el contrato, podemos observar dos posibilidades que implican otras tantas formas distintas de concebir la explotación. De una parte, los arrendamientos por un corto número de años, 9 como máximo, y de otra, los arrendamientos vitalicios. A partir de los datos se puede comprobar que el plazo de tres años es el que se establece con mayor profusión para fijar la duración del contrato con gran diferencia sobre cualquier otra posibilidad relacionada con el corto plazo. La importancia reside en que el arrendamiento corto es un indicador seguro del nivel de penetración del capitalismo en la agricultura

31 Los medievalistas han propuesto clasificaciones de mayor exigencia en cuanto a extensión, teniendo en cuenta que en esos siglos los rendimientos eran bastante bajos de acuerdo con las posibilidades del sistema agrario. Isabel Montes al estudiar las propiedades del cabildo de la catedral de Sevilla distingue en el cultivo del cereal entre un grupo de hazas entre 0,50 y 100 fanegas y otro de más de 100 fanegas. Montes 1989: 207.

32 Un magnífico intento clasificador supone el libro de Ferrer Rodríguez y González Arcas 1996. En los siglos XVI y XVII se emplean indistintamente aranzadas y fanegas. En este trabajo hemos procurado utilizar las fanegas en el caso de las tierras de cereal, asumiendo las pequeñas variaciones comarcales. Por ejemplo, en Sevilla la fanega equivale a 6.440 metros cuadrados y en Carmona a 5.702 .

33 Ladero 1976: 36.

34 Carpio 2004: 476. andaluza. ${ }^{35}$ Según esto, nos encontraríamos con que un sector importante del clero aprovecha sus propiedades de forma moderna con una cierta mentalidad capitalista que estaría atenta a la variabilidad del mercado para conseguir el máximo de rentabilidad. La hipótesis parece sólida, pero necesitada de matizaciones al analizar el comportamiento de los precios.

Respecto a los arrendamientos de por vida hemos podido identificar una clara vinculación con el clero. ${ }^{36}$ Es necesario aclarar que esta forma de explotación resulta fruto más de una intención que de una realidad. Son muchas las ocasiones en las que el fallecimiento $u$ otras circunstancias, como la dejación o dificultades con las fianzas o con los fiadores, el efectivo tiempo de arrendamiento queda reducido a unos cuantos años, incluso, teniendo en cuenta que dichos arrendamientos con el fin de salvar esta posibilidad se firmaban por dos vidas y hasta por tres. El cabildo y la fábrica de la catedral recurrirán insistentemente a esta forma de explotación. ${ }^{37}$ Por otra parte, debemos señalar que los arrendamientos vitalicios se aplicaron a todo tipo de propiedades, no fue un fenómeno exclusivo de las grandes fincas, ni tampoco localizables únicamente en un espacio concreto.

\section{El caso del convento de Santa Clara en Carmona}

En cualquier problemática y, en concreto, respecto al panorama de los bienes rústicos del clero consideramos de utilidad el estudio de caso. A pesar de la heterogeneidad que caracteriza el estamento eclesiástico, abordar el análisis de una institución concreta siempre proporciona conocimiento a la hora de confirmar hipótesis o mostrar otras estrategias o líneas de actuación en cuanto a la gestión del patrimonio. En este sentido, el convento de Santa Clara de Carmona puede resultar de utilidad para fijar un determinado modelo sobre la administración y explotación de las propiedades agrarias. Para ello hemos utilizado una valiosa fuente como el Libro del Protocolo Mayor de la Hacienda y Bienes del muy Ilustre y Magnifico Convento de Nuestra Madre y Señora Santa Clara (1697). Asimismo, hemos seguido la explotación de las propiedades a partir de los contratos conservados en los Protocolos del Archivo de Carmona.

Carmona constituye una de las más importantes villas de realengo del reino de Sevilla. Bastante poblada, se beneficia de la gran fertilidad de sus tierras en una comarca especialmente productiva respecto al cereal de secano, como es la Campiña. ${ }^{38}$ Ese hecho no puede ser ajeno a la intensidad con la que vive el proceso general de crecimiento y difusión de las órdenes religiosas con la fundación de conventos por toda la geografía española. A lo largo del siglo XVII la ciudad concentra, además de 7 parroquias y distintas iglesias eremitas, 11 conventos (6 masculinos y 5 femeninos). En este contexto de tan excesiva presencia eclesiástica sobresale el convento de monjas de Santa Clara. Había sido el primero femenino que se implantó en Carmona, cuando solamente existía el convento masculino de San Sebastián (1447), de la misma orden franciscana. Su fundación se debe a una bula

\footnotetext{
35 Bernal 1988: 162

36 Carpio 2002: 284.

37 Los arrendamientos vitalicios los seguirá utilizando el cabildo hasta comienzos del siglo XIX. Gamero 1998: 126.

38 Carpio 2010: 45.
} 
de Pío II, fechada en $1460 .{ }^{39}$ Desde el principio, cuenta con el apoyo de la pequeña nobleza y la élite local: «asistieron muchas señoras de las principales que había en este pueblo a las dichas fundadoras, unas siendo religiosas y otras con sus caudales siendo favorecidas... $\gg .{ }^{40} \mathrm{~A}$ esto se suma el favor real concediéndoles exenciones y privilegios, especialmente el que otorga en 1511 la reina Juana de Castilla por el que libra al convento de toda carga y tributos concejiles o reales. Por estas mismas fechas resulta decisiva la protección de la duquesa de Arcos, D. a Beatriz Pacheco, con las mandas de su testamento. ${ }^{41}$ La mediación de esta importante señora de la nobleza había logrado bula papal para que «este convento goce de todos los privilegios exenciones de diezmos de subsidios y demás fueros que para el convento de Tordesillas en el año de $1450 »{ }^{42}$

En esta situación de inmunidad fiscal y salvaguarda de rentas el convento llegó a reunir un patrimonio, que le convertía en una de las instituciones más ricas, no solamente de Carmona, sino del todo reino de Sevilla. En fechas tempranas, como 1533, parece ser que poseía unas 140 aranzadas de olivar, tierras de labor que rentaban 800 fanegas de pan terciado y 40.000 maravedís al año en tributos, a los que se sumaban otros 2.500 maravedís de un juro, situados en la alcabala de la carne en Carmona..$^{43} \mathrm{~A}$ finales del siglo XVII, sin contar la propiedad inmobiliaria de casas y alguna atahona y molino, el convento acumulaba 38 propiedades de tierra calma, 1 huerta, 25 olivares, 5 juros y 410 tributos. En definitiva, dos pilares patrimoniales fundamentales: las propiedades rústicas y las rentas de censos, generalmente al quitar, en los que se invertía buena parte de la liquidez monetaria. En este sentido, resulta altamente significativa la indudable apuesta por el crédito privado y el desinterés por la deuda pública. No existe, pues, una excesiva diversificación de bienes, pudiendo llegar a sorprender la total ausencia de una actividad que proporcionaba una alta rentabilidad, como era la ganadería, por otra parte, bastante común en las órdenes regulares andaluzas. En general, se acepta que, en las zonas fértiles de Murcia, Extremadura y Andalucía, existiría una Iglesia terrateniente, mientras que en las zonas de pequeñas explotaciones y tierras pobres las rentas procederían esencialmente de los censos y los juros. ${ }^{44}$ La posición dominante basada en la riqueza se mantuvo durante todo el Antiguo Régimen. Según el catastro de Ensenada, el convento de Santa Clara figuraba como el tercer propietario tras el cabildo de la catedral de Sevilla y el cabildo del concejo de Carmona con las tierras baldías. ${ }^{45}$

El convento se funda con una sólida base económica, por lo que en la dotación inicial figuran ya algunas de las fincas importantes. No obstante, la principal vía de

39 Otorgaba licencia a Teresa y Beatriz Salcedo, hijas de Martín López de Salcedo, perteneciente a la élite local. Libro del Protocolo Mayor de la Hacienda y Bienes del muy llustre y Magnifico Convento de Nuestra Madre y Señora Santa Clara. 1697.

40 Libro del Protocolo Mayor... 1697

41 La consideración de los conventos como centros de poder, con lo que supone de dominio social y perpetuación de status ha sido puesta suficientemente de manifiesto. Atienza 2008: 16.

42 Libro del Protocolo Mayor... 1697.

43 González Jiménez 2006: 146.

44 Catalán 2000: 66

45 Cruz 1980: 94. engrandecimiento del patrimonio y manifiesta riqueza estuvo ligada a las dotes de monja. ${ }^{46}$ Desde el principio fue un destino preferente a la hora de profesar jóvenes procedentes de familias acaudaladas o de la nobleza. Así, como bienes dotales se incorporaron, por ejemplo, cortijos tan importantes como Torrejuelo (448 fanegas) en 1470 o La Motilla (300 fanegas) en 1475. A esta forma directa de crecimiento de la propiedad se añade el medio más utilizado, como es el de las compras. La participación inversora en el mercado de la tierra también guarda relación con el ingreso de novicias y sus correspondientes dotes, aunque fuese mediante un mecanismo indirecto, al aportar no solo bienes rústicos, sino dinero. Como referencia, a finales del siglo $\mathrm{XVI}$ y principios del siglo XVII, las escrituras que se suscriben en torno a las dotes fijan la cantidad de 500 ducados, además de la manutención anual en torno a 24 ducados y un cahiz de trigo y otras cantidades sin concretar, en concepto de regalos de entrada y limosnas. ${ }^{47}$ No siempre se abonan al contado. En muchos casos, estos compromisos se satisfacen directamente en uno o dos plazos y la otra parte se financia con el traspaso de tributos. En cualquiera de las fórmulas empleadas se produce una acumulación de rentas y disposición de liquidez, que invita a la inversión y esta se dirige preferentemente en el siglo XVI a la adquisición de tierra calma. De esta forma, conocemos que el $75 \%$ de los bienes inventariados en 1697 en esta categoría (tierras) ${ }^{48}$ procedían de compras efectuadas mayormente entre 1485 y $1520 .{ }^{49}$ Por ello, González Jiménez afirma que en 1533 el convento disponía ya de unas 1000 hectáreas (1560 fanegas) de tierra de labor. ${ }^{50}$ Desde mediados del siglo XVI, los dominios monásticos andaluces aparecen convertidos en empresas agrarias de carácter racional y rentable. ${ }^{51}$ Estas compras se efectúan sin descuidar el interés por los censos. Atienza afirma que la orientación que con más frecuencia se impuso fue la de que las sumas de las dotes se invirtieran en censos o juros, que importarían una renta anual fija. ${ }^{52}$

Tanto el Libro de Bienes Mayores de la institución, como, sobre todo, los contratos de arrendamiento informan sobre la localización exacta de las propiedades, indicando el lugar ${ }^{53}$ y las lindes con las fincas contiguas. Salvo tres fincas pertenecientes al término de Marchena, todas las demás corresponden a Carmona. En todos los casos parece estar garantizada la calidad y la buena situación respecto al núcleo urbano. La observación de las lindes sugiere una concentración de propiedad en manos de los poderosos, sean eclesiásticos (cabildo de la catedral u otros conventos) o laicos (conde de Gelves, duque de Arcos, etc.). Planteamos la hipótesis de una correspondencia social entre la ciudad y sus barrios y el paisaje agrario. De la misma forma que la vivienda se configura en torno a áreas dominadas por la

\footnotetext{
46 Gómez Navarro 2004: 87.

47 Archivo Municipal de Carmona (AMC) Protocolos 186, 399.

48 Esta denominación de la época va referida exclusivamente al terreno de secano de cultivo cerealístico. Se emplea para las distintas unidades de explotación: hazas y cortijos o donadíos.

49 Libro del Protocolo Mayor... 1697

50 González Jiménez 2012: 1427.

51 Rodríguez Molina 2004: 130

52 Atienza 2008: 359.

53 En algunos lugares, como la ciudad de Sevilla, la localización se denomina pago. En el caso de Carmona se identifica con el término pertenencia.
} 
condición social, la propiedad de las tierras se concentra en espacios casi de exclusividad, de los que el modesto labrador permanece alejado y a los que solamente podría acceder mediante subarriendos.

Una unidad específica de explotación viene dada por los cortinales. Se trata de pequeñas parcelas en el interior del núcleo urbano o en los aledaños inmediatos. ${ }^{54}$ Se dedican, generalmente, al cultivo del cereal. El convento de Santa Clara contaba con cinco cortinales en Carmona. ${ }^{55}$ Todos habían sido comprados, tres de ellos en el siglo XVI y dos en el siglo XVII, estos últimos serían adquiridos en almoneda a muy bajo precio.

El olivar constituía la otra base de las propiedades agrícolas del convento de Santa Clara de Carmona. Las características específicas de este cultivo, como la evolución que conoció en las manos del convento requieren de su propio análisis, el cual no forma parte de este trabajo. No obstante, señalamos las notas más significativas. Según el inventario que implica el Libro Mayor de Bienes la institución llegó a poseer 43 fincas de olivar. A diferencia, de la tierra calma, no es una propiedad inmovilizada. En el siglo XVIII había vendido 9 olivares y adquirido por diversas vías cierto número indeterminado. Según datos de 1763 concentraba poco más de 200 aranzadas, lo que suponía el 12,6 \% del olivar cultivado en Carmona. ${ }^{56}$

En el período que estudiamos de los siglos XVI y XVII el olivar debió tener un papel mucho menor en el conjunto de bienes de Santa Clara. Así lo sugiere su escasa presencia en la documentación. Descontados, algunos pedazos que debieron figurar en la dotación inicial, lo cierto es que durante el siglo XVI no hay constancia de que entraran olivares a incrementar el patrimonio del convento. En cambio, en el siglo XVII existe un notorio interés por este cultivo y una parte de la inversión se destina a la compra de olivares, especialmente en las décadas centrales, entre 1630 y 1660. Otra línea se activa por la vía tradicional, a partir de las dotes que aportan las futuras monjas. Incluso, se dan casos en los que se recurre al trueque, bien de tierra calma por olivares, o bien intercambiando un pedazo de olivar por otro. Una característica común de estas propiedades, a diferencia de la tierra calma, es el alto grado de cargas que soportan, al estar gravadas con numerosos tributos, generalmente en forma de censos que nutren el crédito privado.

En los olivares de Santa Clara predomina la pequeña y mediana propiedad, con pedazos entre 1 y 6 aranzadas, aunque era habitual que cada finca constase de varios pedazos, lo que facilitaría la explotación al poder arrendarse por separado cada una de estas unidades, o bien en su conjunto. ${ }^{57} \mathrm{Al}$ igual que otras instituciones eclesiásticas, como el cabildo de la catedral de Sevilla, la forma más empleada en la explotación del olivar radica en el arrendamiento vitalicio, por una o dos vidas. En este caso, el convento mantiene

54 En la descripción del cortinal del Arbollon se da cuenta de dos trozos de muralla que quedan dentro de la parcela.

55 El cortinal conocido como de la calle de La Sierpe formó parte de un trueque por olivares, en fecha indeterminada, probablemente de siglo XVIII. Igualmente se compraría otro cortinal en 1717.

56 Pilares e Hidalgo 2003: 518

57 El pedazo es la unidad de explotación en el olivar. Se expresa en aranzadas, siendo lo habitual en estos siglos una plantación en torno a 60 olivos por aranzada. Cuando el pedazo sobrepasa las aranzadas se especifican las unidades como pies de olivar. en estos siglos el pago en especie, percibiendo una determinada cantidad de arrobas de aceite. Más excepcional resultaba una fórmula enfitéutica como la cesión a tributo perpetuo, ${ }^{58}$ casi como un recurso para situaciones de crisis acusada en las que es difícil encontrar arrendatarios.

A pesar de que Carmona cuenta con tierras de regadío el cultivo de huerta solamente tiene una presencia testimonial entre los bienes rústicos de Santa Clara. En concreto, solo cuenta con una huerta y en forma de propiedad compartida. ${ }^{59}$ Se explotaba mediante arrendamientos cortos de tres años o, a veces, un solo año. Estipulaba un pago mixto de la renta, en dinero y especie. ${ }^{60}$ En el siglo XVII, la Iglesia le reclama los diezmos sobre esta propiedad, firmándose una concordia en 1663 por la que el convento se reserva la tercera parte de esta renta.

Lo que ofrece abundantemente la documentación notarial sobre Santa Clara son contratos de arrendamientos relativos a sus posesiones de tierras. La explotación de los bienes más importantes de su patrimonio se lleva a cabo, sin lugar a dudas, a través de los arrendamientos, el sistema dominante que se había impuesto en Europa. Vamos a analizar los elementos que se establecen en este tipo de relación económica para intentar entender como significó una estrategia adecuada para este convento femenino a la hora de obtener rendimientos y beneficios, más allá de un mero comportamiento rentista.

A la hora de administrar sus propiedades y, en concreto, escriturar contratos de arrendamiento, el convento de Santa Clara, al igual que otros conventos femeninos, especialmente los de clausura, ${ }^{61}$ se basa en la figura de un administrador profesional conocido como mayordomo. No bastaba con ser un hombre de plena confianza para la institución. La función de representación ejercida adquiría la forma de una relación contractual firmada también ante el escribano público. Si tomamos como ejemplo el nombramiento como mayordomo de Bartolomé Algarín en $1601^{62}$ podemos destacar varias notas significativas:

- La responsabilidad del cargo comprometía también a su esposa con la que otorga el documento ante el escribano.

- Estaba obligado a llevar un libro de cargo donde quedasen registradas todas las operaciones

- Disponía de 90 días como máximo para llevar a cabo las gestiones de cobro a partir de los plazos señalados.

58 En momentos de crisis, como fueron los de principios del siglo XVII, en concreto, en 1605 la fábrica de la iglesia de Santa María de Carmona pregonaba y sacaba a remate público un olivar con la particularidad de que se podía acceder mediante arrendamiento de por vida, a través de tributo perpetuo o de tributo abierto. AMC, Protocolos. 197, 1172.

59 El convento tiene las $3 / 4$ partes de la huerta conocida como Ruigil, perteneciendo la otra parte a los herederos de D. García y D. Hernando de Sotomayor sobre la que se instituyó una capellanía. Había comprado una parte en 1526 y el resto en 1596 con el cargo de 35 reales de tributo perpetuo.

60 «40 ducados y 8 gallinas, 50 libras de azahar y 100 limas o naranjas y todas las hierbas verdes que fuere menester para las fiestas los dineros la mitad por S. Juan y la otra mitad por S. Miguel de 1604. Las gallinas por pascua de navidad de 1603 y las limas y naranjas cuando se os pidiere y el azahar en su tiempo». AMC. 186, 384.

61 Gómez Navarro 2011: 214.

62 AMC, Protocolos, 179, 34. 
- Debía acudir cada día al convento llevando 18 reales para el gasto ordinario de carne y pescado. Los viernes, sábados y días de vigilia debía llevar 12 ducados y además otros 4 ducados para gastos extraordinarios.

- Percibía un salario anual mixto, con predominio del pago en especie. En concreto, 2 cahices de trigo y 2 cahices de cebada por el día de Santiago y 2 arrobas de aceite por Navidad. A ello se sumaba 12.000 maravedís anuales, repartidos en tres pagas cada cuatro meses.

- Cada vez que tuviese que salir de Carmona para cobranza u otra gestión para el convento recibiría 9 reales diarios.

Durante el período estudiado fueron varios los mayordomos que trabajaron para el convento, generalmente por etapas de menos de 5 años. Parece como si la institución quisiera evitar que con el paso del tiempo su representante se relajara en el celo de sus funciones y perdiese efectividad en el cobro de las rentas. Si se producía una dilación injustificada en la percepción de rentas se procedía a otra elección y nombramiento. ${ }^{63}$ Por otro lado, la existencia del mayordomo no impide que las monjas actuaran con autonomía en las decisiones cotidianas de gobierno y administración y que mantuvieran contacto permanente con el exterior. ${ }^{64}$

Los arrendatarios que labran las tierras de Santa Clara también siguen, de forma general, el perfil social que ya hemos señalado para el conjunto de la propiedad eclesiástica. En este caso, vecinos acomodados, con un presumible nivel de renta que le aproxima a la baja nobleza y ocupando cargos concejiles, como el de jurado. ${ }^{65}$ Se trata de personas solventes y pertenecientes a familias de confianza. En algún caso, incluso, de su círculo próximo, pues han ejercido de mayordomos para el convento. En esta línea de confianza, tal vez se pueda considerar los contratos que se establecen con clérigos, sobre los que se especifica que ya labraban previamente esas tierras. Estas renovaciones afectan a diversos arrendatarios y constituyen un ejemplo frecuente. Denotan la satisfacción de ambas partes ante lo que esperan alcanzar en la relación económica acordada. Esto no impide que el convento en el comportamiento capitalista que implican los arrendamientos a corto plazo no lleve a cabo, si las circunstancias lo aconsejan, una revisión al alza de la renta. ${ }^{66}$ Existe la tendencia de mantener la relación de una familia con una

63 En 1595 cuando es nombrado Juan de Salamanca, su antecesor Juan Naranjo debía al convento 165.800 maravedís en 6 partidas, que se compromete a cobrar el nuevo mayordomo, lo que repercutirá en su salario. AMC. 154, 612

64 Rey Castelao 2009b: 74.

65 Tanto Martín Gascón, regidor, como Francisco Gascón toman en arrendamiento diversas propiedades del convento en distintos momentos. El segundo, debía ser un acaudalado labrador, del que detectamos una intensa participación en un negocio tan rentable como el del arrendamiento de bueyes.

66 En 1606 arrienda a Hernando Gutiérrez la haza de Marmolejo por tres años con un precio cada año de 30 fanegas de pan terciado y 5 gallinas y se renueva en 1608 antes de finalizar su vigencia por otros tres años, pero con una renta de 40 fanegas y las 5 gallinas. Este labrador conocía bien las posibilidades de estas tierras, pues ya anteriormente las había arrendado junto con un socio, Juan de Ojeda, por 36 fanegas de pan terciado y 3 pares de gallinas, lo que demuestra las oscilaciones en la revisión de la renta. AMC. 177; 186, 197, 661 y 203, 29. determinada propiedad. Es la misma estrategia que seguía el cabildo de la catedral con los arrendamientos vitalicios al intentar contar con arrendatarios fiables, que alejaran la posibilidad de pleitos. ${ }^{67}$ Toda esta política se inscribe en el marco de economía comarcal, por lo que, entre los arrendatarios de las propiedades del convento, tanto de las de Carmona como de las de Marchena, resulta común encontrar vecinos de las localidades próximas: Fuentes, El Arahal, Mairena, Paradas.

Las tierras de Santa Clara, incluso en el caso de los cortijos, estaban divididas en grandes hazas. ${ }^{68}$ Esta configuración del espacio agrario facilitaba que los arrendamientos se efectuasen sobre las fincas completas, los cortijos, o sobre las unidades menores, las parcelas de hazas. Al repercutir esta última estrategia de explotación en un mayor número de arrendatarios se podría considerar que el convento optimizaba la rentabilidad de sus posesiones con la percepción de más rentas. No obstante, no existe un único procedimiento y también existen casos en los que un mismo colono arrienda al mismo tiempo dos cortijos. ${ }^{69}$

El modelo tipo de arrendamiento que emplea el convento de Santa Clara, basado en el tiempo de duración de tres años, es el más común en el campo sevillano durante los siglos XVI y XVII. Su incidencia es del $80 \%$ de los contratos estipulados. La misma proporción del 9,5\% representan los plazos de dos y cuatro años, quedando un insignificante $1 \%$ para los contratos de cinco años. Lo que en ningún momento forma parte de las estrategias del convento es el arrendamiento vitalicio, lo que le convierte en una de las características más singulares en la gestión de su patrimonio. Otras importantes instituciones, como el cabildo de la catedral, hacen del arrendamiento vitalicio su principal instrumento en la administración de sus propiedades rústicas, incluidas las muy numerosas en el área de Carmona. Puede interpretarse que ni siquiera en los momentos de crisis se reduciría sustancialmente el potencial de candidatos dispuestos a labrar las tierras del convento, por lo que este no debió sentir la presión de quedarse sin arrendatarios de garantías para sus propiedades. ${ }^{70}$ En otro ámbito de gestión del patrimonio en la primera década del siglo XVII, caracterizada como de profunda crisis en Carmona, la documentación muestra repetidos ejemplos en los que el convento se adapta a los duros tiempos aceptando diferentes bajadas o descuentos en los tributos que percibían. Nada similar hallamos respecto a las tierras.

Otra singularidad de Santa Clara radica en la naturaleza de la renta, ya que solamente practica el cobro en especie. Se trata siempre de pan terciado, que el colono ha de encargarse de poner (encamarar) en los almacenes del convento a tal efecto. Esta constante decisión de guardar el grano y monetarizar el producto en el momento más aconsejable del mercado nos pone una vez más de manifiesto la

67 Carpio 2004: 477.

68 Solamente una propiedad, el cortijo de Bentosilla, está formado por una sola haza de 344 fanegas.

69 En 1606 Francisco Gascón Úbeda arrendaba dos cortijos, Parias y Bentosilla, durante dos años. AMC 197, 14.

70 En ocasiones pudo darse el fenómeno contrario con una dura competencia en las pujas del remate. Eso parece indicar cuando el participante que gana la subasta había ofrecido 100 reales de limosna para el convento a pagar en una sola vez, además de la renta establecida previamente. AMC. 203, 1015. 
mentalidad capitalista, plenamente pendiente de la optimización de los recursos y la búsqueda de las mayores ganancias. Al pan terciado, habitualmente se añadían gallinas, ${ }^{71}$ en proporción a la renta de cereal y también en cantidades menores garbanzos ( 1 fanega) y paja ( 2 cargas). La singularidad responde al ámbito sevillano, donde se ha impuesto la renta en dinero. En otras latitudes, como Galicia, los patrimonios de los monasterios se evaluaban en rentas en especie. $^{72}$

Un importante aspecto en los arrendamientos, como las cláusulas del contrato, el convento lo somete a la uniformidad de un modelo previo en el que se encajan la casi totalidad de las situaciones, sin apenas particularidades que se aparten entre lo previamente establecido por la propia institución para la relación económica entre arrendador y arrendatario. Lo más interesante afecta a la conocida cláusula de esterilidad..$^{73} \mathrm{El}$ colono tiene que sembrar la cantidad suficiente para pagar la renta, al menos la mitad de las tierras y ha de hacerlo sobre buenos barbechos para llegado el caso estar en disposición de solicitar la aplicación del procedimiento de esterilidad encaminado a conseguir un descuento de la renta. En cualquier caso, el convento establece que se ha de pagar como mínimo la sexta parte (el sexmo) de todo el año. Los productos complementarios, como los garbanzos o las gallinas, permanecen al margen de esta eventualidad.

Una fórmula común en el campo sevillano y que también sería practicada por el convento de Santa Clara, en más contadas ocasiones, corresponde a los terrazgos. En todos los que recurre a este tipo de contrato se fija una duración de un año, una sola cosecha por la que se pagaba una renta equivalente a la superficie labrada, una fanega por cada fanega sembrada. Esto llevaba a la obligatoriedad, especificada, en las escrituras de medir la extensión cultivada.

\section{CONCLUSIONES}

En primer lugar, conviene resaltar la idoneidad de las fuentes en función de los objetivos planteados. La disponibilidad de documentos generales, como pueden considerarse los protocolos notariales, nos acerca a ciertos aspectos económicos de cualquier grupo social, como en este caso el clero. No obstante, la existencia de fuentes eclesiásticas específicas de una determinada comunidad religiosa permite mayor profundización en el análisis, así como contraponer las dinámicas observadas con el comportamiento particular a la hora de seguir una determinada estrategia a través del estudio concreto de un caso. La documentación de Santa Clara de Carmona ilustra, incluso, sobre el origen de sus propiedades, destacando el papel de las compras.

71 Las gallinas se reclaman vivas $y$, en menor medida sustituidas por una equivalencia en dinero. Excepcionalmente se combinan ambas cosas. En 1607 en un precio de arrendamiento se incluyen 12 gallinas ( 7 en pluma y 5 en dineros a 4 reales cada una). AMC. 199, 672 Sin embargo, el cabildo de la catedral, gran perceptor de gallinas, tanto de sus bienes inmobiliarios como rústicos, establecía un valor monetario medio de la gallina y se cobraba el total en moneda. Hernández 2010: 56.

72 Saavedra 2018: 10.
El peso de la economía agraria en los siglos XVI y XVII parece estar fuera de toda duda. Siendo tal su importancia consideramos congruente que un estamento, como el clero, que ocupa una posición dominante en esa sociedad, cuente con una implicación muy directa en esta actividad. En líneas generales, una de las bases en las que se sustenta el poder temporal de la Iglesia reside en la cantidad y calidad de un extenso patrimonio rústico. A pesar de la gran heterogeneidad que caracteriza este estamento y enormes diferencias en cuanto a su riqueza, la tierra constituye una de sus principales fuentes de ingreso.

En Andalucía y, más concretamente, en el reino de Sevilla, las propiedades eclesiásticas siguen el modelo de explotación dominante ya en Europa desde el siglo XVI, es decir, los arrendamientos. No obstante, esta afirmación siempre estaría necesitada de matizaciones, tanto en la evolución temporal, como en su aplicación según los distintos cultivos. Por lo que conocemos, la presencia del clero se relaciona con todo tipo de cultivos. La documentación estudiada confirma el peso de lo que hemos denominado participación institucional, es decir, no la de un miembro individual del clero, sino la de cualquiera de los colectivos o comunidades que forman parte de este estamento. Contando con la diversidad que caracteriza este ámbito institucional sobresale por su elevado número y forma de actuación los arrendamientos efectuados por los conventos y monasterios de las órdenes regulares

Sabemos que no existió un modelo único de gestión, pero seguimos necesitando estudios que afronten una problemática tan amplia y compleja, marcada por la heterogeneidad de las instituciones que conforman el clero, además de las particularidades geográficas. ¿Dispone el clero regular de sus propias estrategias distintas de las del clero secular? El estudio de un caso, como el convento de Santa Clara, nos permite confirmar como dentro de un marco general en las relaciones económicas, cada institución puede marcar su propia línea de gestión en muy diversas cuestiones. Un ejemplo de ello puede encontrarse en el modelo de percepción de rentas, con la exclusividad del pago en especie, en unos momentos en los que este sistema va dejando paso a las rentas en dinero.

De cualquier manera, sean cual sean las prácticas con las que se aborde la gestión del patrimonio rústico eclesiástico, se hace patente una preocupación por la rentabilidad. La profesionalización de la figura del mayordomo que administra los bienes confirma esta interpretación. Sin descuidar la tradicional sensibilidad por la seguridad de sus bienes, la mayor parte de las decisiones adoptadas van encaminadas a una optimización del beneficio. En todas las formas de explotación y, muy especialmente en los arrendamientos, se redactan los contratos con cláusulas que, además de garantizar la buena conservación de la propiedad, salvaguarden también unas ganancias que no están sometidas al riesgo implícito en la actividad agraria. Esta actitud queda muy alejada de un propietario rentista despreocupado de la administración de sus bienes que parece desprenderse de una parte de la historiografía. 


\section{BiBLIOgRAFÍA}

Álvarez Vázquez, José Antonio. 1984. «Evolución de los arrendamientos agrícolas de 1450 a 1850 en Zamora». En Congreso de Historia Rural. Siglos XV al XIX, 613-623. Madrid: Universidad Complutense.

Atienza López, Ángela. 2008. Tiempos de conventos. Una historia social de las fundaciones en la España Moderna. Madrid: Marcial Pons.

Benítez Barea, Avelina. 2013. Clero y mundo rural en el siglo XVIII. La comarca gaditana de la Janda. Cádiz: Universidad.

Bernal Rodríguez, Antonio Miguel. 1988. Economía e historia de los latifundios. Madrid: Instituto de España. Espasa-Calpe.

Borrero Fernández, Mercedes. 2003. La organización del trabajo. De la explotación de la tierra a las relaciones laborales en el campo andaluz (siglos XIII-XVI). Sevilla: Universidad.

Candau Chacón, María Luisa. 1994. El clero rural de Sevilla en el siglo XVIII. Sevilla: Caja Rural de Sevilla.

Carpio Elías, Juan. 2002. «Un sistema de explotación en las propiedades rústicas del Antiguo Régimen: los arrendamientos de por vida». En Actas del III Congreso de Historia de Andalucía. Historia Moderna, Tomo I, 283-297. Córdoba: Obra Social y Cultural Cajasur.

Carpio Elías, Juan. 2004. «Propiedad rústica eclesiástica en Carmona. Siglos XVI-XVI|». En El mundo rural en la España Moderna, coordinado por Francisco José Aranda Pérez, 467-482. Cuenca: Ediciones de la Universidad de Castilla-La Mancha.

Carpio Elías, Juan. 2010. La explotación de la tierra en la Sevilla de los siglos XVI y XVII. Sevilla: Diputación Provincial.

Carpio Elías, Juan. 2011. «Los contratos de medianería en la explotación de las tierras de Carmona (2 - mitad del siglo XVI)». En Carmona, 7000 años de historia rural, 361-380. Carmona: Ayuntamiento y Universidad de Sevilla.

Carpio Elías, Juan. 2017. «Intervencionismo estatal y respuesta local ante la crisis de cereales de 1584 en Palma del Río». Tiempos Modernos 34. 151-166.

Catalán Martínez, Elena. 2000. El precio del purgatorio. Los ingresos del clero vasco en la Edad Moderna. Bilbao: Universidad del País Vasco.

Chacón Jiménez, Francisco. 1984. «Los arrendamientos como sistema de trabajo de la tierra durante el Antiguo Régimen en el reino de Murcia». En Congreso de Historia Rural. Siglos XV al XIX, 625-644. Madrid: Universidad Complutense.

Cruz Villalón, Josefina. 1980. Propiedad y uso de la tierra en la Baja Andalucía. Carmona, siglos XVIII-XX. Madrid: Servicio de Publicaciones del Ministerio de Agricultura.

Domínguez Ortiz, Antonio. 1973. Las clases privilegiadas en el Antiguo Régimen. Madrid: Ediciones Istmo.

Ferrer Rodríguez, Amparo y Arturo González Arcas. 1996. Las medidas de tierra en Andalucía. Según las Respuestas Generales del Catastro de Ensenada. Madrid: Alcabala del Viento. Tabapress.

Gamero Rojas, Mercedes. 1998. "Los contratos de arrendamiento de las grandes unidades de explotación en la Baja Andalucía (SS. XVI-XIX)». En En torno a la documentación notarial y a la Historia, coordinado por Pilar Ostos Salcedo y María Luisa Pardo Rodríguez, 125-142. Sevilla: Ilustre Colegio Notarial de Sevilla.

Gómez Navarro, Soledad. 2004. «A punto de profesar: las dotes de monjas en la España Moderna. Una propuesta metodológica». En La clausura femenina en España, coordinado por Francisco Javier
Campos y Fernández de Sevilla, Vol. 1, 83-98. San Lorenzo de El Escorial: Estudios Superiores del Escorial.

Gómez Navarro, Soledad. 2011. «De rejas adentro: monjas y religiosas en la España Moderna. Una historia de diferencias en la igualdad». Revista de Historia Moderna 29: 205-227.

González Jiménez, Manuel. 2006. Carmona medieval. Sevilla: Ayuntamiento de Carmona y Fundación José Manuel Lara.

González Jiménez, Manuel. 2012. «El latifundio en Carmona: del repartimiento a los tiempos modernos». En Mundos medievales: espacios, sociedades y poder II. En Homenaje al profesor José Ángel García de Cortázar y Ruiz de Aguirre, editado por Beatriz Arízaga Bolumburu, 1417-1432. Santander: Universidad de Cantabria.

Hernández Borreguero, José Julián. 2010. La catedral de Sevilla. Economía y esplendor (siglos XVI y XVII). Sevilla: Ayuntamiento.

Herrera García, Antonio. 1980. El Aljarafe sevillano durante el Antiguo Régimen. Sevilla: Diputación Provincial.

Ladero Quesada, Miguel Ángel. 1976. «Donadíos en Sevilla. Algunas notas sobre el régimen de la tierra hacia 1500». Archivo Hispalense 181: 19-92.

López Martínez, Antonio Luis. 1992. La economía de las órdenes religiosas en el Antiguo Régimen: sus propiedades y rentas en el reino de Sevilla. Sevilla: Diputación Provincial.

Marcos Martín, Alberto. 2000. España en los siglos XVI, XVII y XVIII. Economía y Sociedad. Barcelona: Crítica/Caja Duero.

Montes Romero-Camacho, Isabel. 1989. El paisaje rural sevillano en la Baja Edad Media. Aproximación a su estudio a través de las propiedades territoriales del Cabildo-Catedral de Sevilla. Sevilla: Diputación Provincial.

Pérez Rubio, Laureano. 2013. «Párrocos, parroquias y concejos: el modelo parroquial leonés en el marco de las comunidades rurales y concejiles durante la Edad Moderna». Obradoiro de Historia Moderna 22: 129-166. https://doi.org/10.15304/ohm.22.1011

Pilares Fernández, Francisco y Fernando Hidalgo Lerdo de Tejada. 2003. «El clero regular y sus propiedades agrícolas en Carmona en 1763». En Carmona en la Edad Moderna, editado por Manuel González Jiménez, 515-520. Carmona: Ayuntamiento de Carmona y Universidad de Sevilla.

Rey Castelao, Ofelia. 2009a. "Las Economías monásticas femeninas: un estado de la cuestión». En La Historia de Las Mujeres: Perspectivas actuales, dirigido por Cristina Borderías, 197-223. Barcelona: Icaria editorial.

Rey Castelao, Ofelia. 2009b. «Las instituciones monásticas femeninas ¿centros de producción?». Manuscrits 27: 59-76.

Rodríguez Molina, José. 2004. «Patrimonio y rentas de la Iglesia en Andalucía». En La Iglesia en el mundo medieval y moderno, coordinado por María Desamparados Martínez Sampedro y María Dolores Segura del Pino, 113-142. Almería: Instituto de Estudios Almerienses.

Saavedra Fernández, Pegerto. 2018. «El control de los patrimonios monásticos en la Galicia moderna». Historia Agraria 74: 7-36.

Sánchez Herrero, José. 2003. «El clero. La organización eclesiástica y la religiosidad cristiana en Carmona durante los siglos XVI, XVII y XVIII». En Historia de Carmona en la Edad Moderna, editado por Manuel González Jiménez, 427-461. Carmona: Ayuntamiento y Universidad de Sevilla. 